\title{
Study on the Formation Mechanism of Energy Prices
}

\author{
Haiwen Long ${ }^{1,2}$ \\ ${ }^{1}$ Oxbridge College, Kunming University of Science and Technology, Kunming, 650106 \\ ${ }^{2}$ School of Economics, Yunnan University, Kunming, 650091
}

KEYWORDS: Energy Price Mechanism; Energy Demand; Economy Development

\begin{abstract}
Research on energy price formation mechanism both in theory and in practice are in constant development. The one hand, new technologies and new patterns of behavior appears to make energy in the production process needs to process more information. The role of different kinds of information in the energy price formation is in the increasingly prominent, so that energy pricing more complex. The second is the need to constantly deal with complex balance multiple objectives, these objectives can be both energy consumers want low prices, high quality, safe and reliable service; it may be energy producers hope that the rapid development of enterprise, constantly updated technology, obtain a higher return on investment; or the government wants the state's energy policy can be carried through and the like. Therefore, the research in complicated conditions, energy pricing mechanism and optimization issue has become one of the forefront issues of economics research.
\end{abstract}

\section{Introduction}

From a global perspective, the energy crisis of the 1970s to make energy price reform has become a global trend. The overall direction of the world energy price reform is to relax government regulation, to break the monopoly and let the market mechanism into full play the role. This trend in the late 1980s and early 1990s more pronounced. Because different countries have very different aspects of the level of economic development, energy market structure, developed in the US, the UK market mechanism in broadening and deepening the process of reform including direct and indirect financial subsidies, financing policy, environment standard, regional market integration, trade protection measures (such as import quotas) and other aspects, these reforms are in the institutional framework of the market economy, the purpose is to improve and optimize the institutional framework has been established markets. Many developing countries are still carried out by non-market system to a market system of the transformation process, including the reform of ownership structure, industrial organization structure, price structure, investment and financing system, taxation system, distribution system, foreign trade system, the government management system, the legal system and a series of reforms. Energy price reform, since the energy pricing mechanism plays a fundamental role as the central issue of reform.

Overall, the study of energy price formation mechanism both in theory and in practice are in constant development. The one hand, new technologies and new patterns of behavior appears to make energy in the production process needs to process more information. The role of different kinds of information in the energy price formation is in the increasingly prominent, so that energy pricing more complex. The second is the need to constantly deal with complex balance multiple objectives, these objectives can be both energy consumers want low prices, high quality, safe and 
reliable service; it may be energy producers hope that the rapid development of enterprise, constantly updated technology, obtain a higher return on investment; or the government wants the state's energy policy can be carried through and the like. Therefore, the research in complicated conditions, energy pricing mechanism and optimization issue has become one of the economic research frontier issues

\section{Energy Initial Price Determination Mechanism}

In a market economy, the size of the commodity value depends on utility and scarcity of the article. Since the energy utility and scarcity has to meet these two conditions, a valuable commodity. Development and utilization of energy in the process is bound to establish ownership relations. Property is a modern market economy is an important concept, visually speaking, property is property rights. H. Demsetz that "the so-called property rights, meaning the rights of others and their own earnings." "Trading in the market once reached, two equity swap took place, although a group of eleven property often attached to goods or services, but the value of the exchange or service is determined by the value of the property." From this explanation, it is the property of goods or services related to a series of rights or a set of rights. E. G. Rupp rich meal and so that "the relationship between people and objects instead of property between, but because of the existence and use thereof caused by the behavior of some of the recognized relationship." "Social prevailing system of property rights can be described as defining the position of each individual in the use of scarce resources, a set of economic and social relations." Therefore, the property is the foundation of economic operation, the core of goods and services trading in the transfer of property rights, property right is prerequisite for the transaction.

Property prices are paid to obtain energy law and the transfer of energy such intangible property prices. Specifically, the price can be divided into prospecting and mining rights price. Worldwide, the price formation mechanism is still in the exploration stage of exploration, and mining rights price formation mechanism, the international community has accepted practice.

Replacement cost method, also known as cost effectiveness survey method. The basic principle of replacement cost method is: the value of exploration of some low level of exploration can be expressed as exploration costs through the present value of the utility factor correction. The principle of replacement cost method is based on the consideration that, in reality, there is a low level of exploration of some exploration, which is characterized by little investment in exploration work usually only area of geological, geophysical and geochemical survey the amount of work and a few engineering prospecting, geological obtained mineral limited information, find the prospect of useful elements enriched geological body is unclear, or even be able to delineate the mineralized bodies, the available information is not sufficient to estimate the amount of resources. However, the analysis of geological conditions, as well as the value of further exploration of these exploration.

Geological prospecting method is a sequence feature commentary by Canadian geologist assessment methodology proposed in 1990 Kilborn "Geological Engineering Law" evolved. Geological feature wood-based assessment principle order law assessment of resource utilization potential and prospects object prospecting exploration investment decision utility size, determines the value of the mining rights. Depending on data exploration area, exploration of the impact of the value of seven essential geological elements: regional metallogenic geological conditions show, geophysical and geochemical anomalies show that mineralization intensity and the size of reserves shows ore processing technology performance display, mining conditions display, minerals and mining rights market conditions show that infrastructure show, subjective evaluation which indicates the potential for further prospecting and exploration area value index promising resource 
utilization, and exploration investment in real replacement cost should be amended to achieve the exploration appraised value.

The initial price formation mechanism of coal and coal industry management system is closely related. For a long time, China's coal industry is in the central and local levels management system. After the reform and opening up, in order to accelerate the development of the coal industry, has established a number of township coal mines, coal mine belongs to a different implementation of different energy prices. Since 1996, the central coal mines all delegated to local jurisdiction by the local. Coal prices also increased from countries multistage guided into market pricing.

\section{Energy Infrastructure Access of Pricing Mechanism}

At present, China is in the access price of energy infrastructure, to take place by governments, according to "reasonable costs, reasonable profit, tax law, social equity" principle, the implementation of a unified policy, hierarchical management. According to the characteristics of different services, network services can be divided into common price, the price of services designed to support services and prices. Special service prices into special price engineering services and networking price categories. Common network service price by the average selling price of energy deducting the average purchase price of the initial energy and transport after determining loss, revenue management transition gradually add to the cost. Permit revenue dedicated engineering services price the government price departments approved on the basis of the development. Networking price to permit income approved based on two cases developed. Networking project no long-term deal, the price of the implementation of networking unitary price, long-term deal with networking engineering, networking price system implemented two price. Specifically, the Government according to the different stages of the characteristics and energy price reform of energy of different characteristics, in determining the price of access to energy infrastructure to take on different pricing models. Select a study of network access pricing mechanism to analyze other energy infrastructure access pricing mechanism (such as access to natural gas and oil pipeline price formation mechanism) is similar to the grid.

In recent years, due to lack of investment in energy infrastructure, and gradually become the bottleneck of development, government and regulatory authorities began to pay attention to energy infrastructure access price formation mechanism optimized to achieve the premise of ensuring the interests of consumers, energy producers to mobilize the enthusiasm of The goal. Specifically, at this stage in the implementation process, the main use of the incremental cost pricing and price cap regulation method.

At present only a part of the electricity in the form of a pilot realized the bidding. In the bidding process, our policy is based on the supply side of the offer auction bidding pricing mechanism, Marginal offer a unified market-clearing price. If China East China Power Market tentatively set a maximum bid by East China Power Grid average unit tariff of 1.25 times the execution (ie: peak hours 482.0 yuan/MWh; time low 321.0 yuan/MWh). The basic operation of the electricity market rules also specify provisions in the electricity market to the highest and lowest market price, the highest and lowest price approved by the general.

The main objective of the establishment of tariff highest price competitive environment constraints model include the following. First, the pricing model should be conducive to encouraging investment in power grid. Cost of return guaranteed investment return on the grid capital, hence the menu regulation will reduce the risk of investment in the grid, help encourage investment. Secondly, the price incentive model should help improve plant efficiency. Fixed price selection of low-cost power plants to improve the efficiency of stimulation, but the cost of the 
contract in return can not achieve such incentives. Again, the price of the model should help reduce operational risks grid. Minimum, you can make the grid run risk aversion by Regulation goals into electric power purchase costs. Finally, the price regulation model should help improve efficiency. With respect to the regulation of the cost of the original regulation means for the government needed a smaller, mainly in access and reduce post-supervision costs decrease information costs.

\section{Conclusion}

Generalized virtual economic theory greatly expands the new thinking energy research pricing mechanism for energy price reform gives some new ideas, including: First, the price of different energy sources as well as energy production constitute different aspects of formation, build a scientific energy value based system, fully reflects the value of the virtual energy; the second is to cultivate energy market as soon as possible to improve the responsiveness of market supply and demand, prices fully reflect market supply and demand virtual form with an effective energy pricing system energy supply and demand interaction; third is to improve the energy market system , especially in the energy and energy technology markets in financial markets, to provide a solid technical guarantee for the energy value of the virtual, virtual price guarantee energy transfer and implementation; fourth is to take full account of the virtual energy prices corrected to improve the efficiency and effectiveness of the control of energy policy .

\section{Reference:}

[1] Allenby, G., and P. Lenk. Modeling Household Purchase Behavior with Logistic Normal Regression [J]. Journal of the American Statistical Association 1994 (89), pp. 669-679.

[2] Amundsen, E. S., Mortensen, J. B. (2001): The Danish Green Certificate System: some simple analytical results [J]. Energy Economics, 23, 5, pp 489-509.

[3] Jinwoo Kim Hierarchical Structure of Intranet Functions and Their Relative Importance:. Using the Analytic Hierarchy Process for Virtual Organizations [J]. Decision Support Systems, 1998, 23:. 59-74.

[4] Jingzhi Guo, Angelina Chow and Rolf T. Wigand. Virtual Wealth Protection through Virtual Money Exchange. Electronic Commerce Research and Applications, 10 (3), May-Jun 2011: 313-330.

[5] Dong Hee Shin, Understanding purchasing behaviors in a virtual economy: Consumer behavior involving virtual currency in Web 2.0 communities Original Research Article, interacting with Computers, Volume 20, Issues 4-5, September 2008: 433-446. 